Article

\title{
Antigenotoxicity and Tumor Growing Inhibition by Leafy Brassica carinata and Sinigrin
}

\author{
María-Dolores Lozano-Baena ${ }^{1}$, Inmaculada Tasset ${ }^{2}$, Sara Obregón-Cano ${ }^{1}$, \\ Antonio de Haro-Bailon ${ }^{1, *}$, Andrés Muñoz-Serrano ${ }^{3}$ and Ángeles Alonso-Moraga ${ }^{3}$ \\ 1 Department of Plant Breeding, Institute of Sustainable Agriculture, CSIC, \\ Avd. Menendez Pidal s/n, Córdoba E-14004, Spain; E-Mails: mdlozano@ias.csic.es (M.-D.L.-B.); \\ saraobregon@ias.csic.es (S.O.-C.) \\ 2 Department of Developmental and Molecular Biology, Chanin Building, Albert Einstein College of \\ Medicine, 1300 Morris Park Avenue, Bronx, NY 10461, USA; E-Mail: b72tacui@uco.es \\ 3 Department of Genetics, Gregor Mendel Building, University of Córdoba, Rabanales, \\ Córdoba 14014, Spain; E-Mails: ge1ams@uco.es (A.M.-S.); ge1almoa@uco.es (A.A.-M.) \\ * Author to whom correspondence should be addressed; E-Mail: adeharobailon@ias.csic.es; \\ Tel.: +34-957-499-235; Fax: +34-957-499-252.
}

Academic Editor: Maurizio Battino

Received: 26 June 2015 / Accepted: 25 August 2015 / Published: 28 August 2015

\begin{abstract}
Cruciferous vegetables are well known and worldwide consumed due to their health benefits and cancer prevention properties. As a desirable cruciferous plant, Ethiopian mustard (Brassica carinata A. Braun) and its glucosinolate sinigrin were tested in the in vivo Drosophila melanogaster (SMART) and the in vitro HL60 (human promyelocytic leukaemia cell line) systems. High performance liquid chromatography (HPLC) analysis of plant samples confirmed the presence of sinigrin as principal B. carinata glucosinolate. SMART was performed by feeding $D$. melanogaster larvae either with different concentrations of plant/compound samples or combining them with hydrogen peroxide (a potent oxidative mutagen) being both antimutagenics. HL60 assays showed the tumoricidal activity of plant samples $\left(\mathrm{IC}_{50}=0.28 \mathrm{mg} \cdot \mathrm{mL}^{-1}\right.$ ) and the breakdown products of sinigrin hydrolysis $\left(\mathrm{IC}_{50}=2.71 \mu \mathrm{M}\right)$. Our results enhance the potential of $B$. carinata as health promoter and chemopreventive in both systems and the leading role of sinigrin in these effects.
\end{abstract}


Keywords: Drosophila melanogaster; HL60; antigenotoxicity; cytotoxicity; Brassica; sinigrin; bioactive compound

\section{Introduction}

There is a wide range of variation with respect to the properties of the botanical products used by humans. The active principles of vegetables constitute nowadays the basis of most pharmacological substances. In this sense, consumers not only appreciate vegetables for their nutritional value, but also for their contents in compounds that produce benefits for human health. For this reason, the analysis of the possible antimutagenic, anticarcinogenic and anti-aging activity of a botanical nutraceutical substance is essential as a tool to distinguish between medicines and simply healthy products.

Many beneficial properties have been attributed to cruciferous vegetables (i.e., broccoli, cabbage, Brussels sprouts and cauliflower) [1,2]. Specifically, numerous members of the Brassicaceae family are commercialized for animal and human consumption around the world as a rich source of nutrients and also, as healthy products [3].

Glucosinolates ( $\beta$-thioglucoside- $N$-hydroxysulphates, GLSs) are naturally occurring thioglucosides that are characteristic of the Brassicaceae (including the genus Brassica) and related family in the order Capparales [4]. These compounds remain inactive until hydrolysed to numerous compounds (thiocyanates, thiones, indoles, nitriles, etc.) which possess diverse biological activities as biocides by myrosinase enzymes (thioglucosidase) [5,6]. They are also known to possess anti-nutritional properties [7] although produce different effects in humans in function of their chemical structure and concentration in the plant. Both vary considerably depending on the species, stage of development, type of tissue and environmental conditions, making the determination of harmful and beneficial effects in human nutrition a difficult task [3].

Brassica carinata A. Braun, commonly known as Ethiopian mustard or Abyssinian mustard, belongs to the Brassicaceae family and is a traditional African vegetable, previously gathered from the wild for human consumption. It is cultivated as an oil and leafy vegetable plant in the Ethiopian highlands at altitudes between 1500 and $2600 \mathrm{~m}$. It is known as yabesha gomen in Amharic and also used in East and Southern Africa as accompaniment for ugali (a type of porridge made from maize or millet flour) $[8,9]$. B. carinata is an annual plant with many desirable traits for commercialization: high yielding and rusticity, edible leaves, resistance to disease and low chemical input requirement $[10,11]$. The plant may be eaten whole and possess a higher nutrient composition than other dietary species like white cabbage and spinach [12].

The predominant GLS in B. carinata is sinigrin, but its concentration depends on different factors, such as genotype, tissues and plant age [13]. Sinigrin hydrolysis catalyzed by myrosinase enzymes produces isothiocyanates (ITCs) as bioactive products [14,15], specifically allyl-ITCs (AITC) whose anticancer activity has been proved by several authors [16-18]. It has been confirmed that even short-term intake of ITC-containing vegetables might be associated with reduced cancer risk in human in vitro and in vivo systems [19]. 
Epidemiological studies highlight that the present consumption rate of this vegetables has benefits for human health even more than diets rich in fruits and other vegetables [20]. However, in vivo and in vitro experiments show variable results depending on the species, and GLS type and content seem to be the key. The present work is based on the need to clarify the balance of adverse and beneficial effects of cruciferous plants already selected for their desirable traits. This is the case of tested plant, the leaves of $B$. carinata, which has been used to determine the antimutagenic and antiproliferative capacities of plant samples and its major GLS sinigrin, as well as the concentrations and time at which their health benefit appears. The Drosophila melanogaster in vivo animal model and the HL60 in vitro cell-line model were used for these two purposes.

\section{Results and Discussion}

Depending on nutrient content, vegetables are categorized into five groups and cruciferous plants fall into two of them [21]: the dark-green and the other vegetables categories, being the dark-green one of the main recommended group for human intake. Information about vegetables and diet, including how much of these foods should be eaten daily or weekly is available from the U.S. Department of Agriculture (USDA) website Choose My Plate.

Due to the large variety among cruciferous species and the high variability of their compound content, the daily human intake of Brassica sp. and GLSs is difficult to estimate. During the past decades, commercial varieties of broccoli have been consumed as most popular Brassica species in a range of 2-8 grams per day around the world, much less than those recommended for total vegetable intake [6]. Also, the corresponding daily GLSs intake in humans is very variable depending on countries and populations, as well as consumed varieties, but it has been estimated to be in the order of milligrams [22]. Despite the great amount of works and studies about this topic, nowadays there are no specific recommendations for only Brassica intake apart from those for general vegetables. However, a current intake assessment conducted by Spherix indicated that the mean and 90th percentile consumption of 16.4 and 50.9 grams per day, respectively, is less than one serving of vegetables (one serving of raw broccoli is $36 \mathrm{~g}$; one serving of cooked broccoli is $78 \mathrm{~g}$ [23]. Taking into account the average daily food intake of $D$. melanogaster (between three to five times its own weight) [24] and its average body weight (1 mg) [25], the concentration ranges assayed for both B. carinata and sinigrin falls within this consumption rate.

\subsection{Leaf Glucosinolate Content Determination}

The HPLC chromatogram of the analysed leaf samples is shown in Figure 1. Only two GLSs were detected: sinigrin (2-propenyl-GLS) $\left(10.05 \mu \mathrm{mol} \cdot \mathrm{g}^{-1}\right.$ of dry weight, DW) and glucobrassicin (3-indolylmethyl-GLS), the last one in small amounts $\left(0.14 \mu \mathrm{mol} \cdot \mathrm{g}^{-1} \mathrm{DW}\right)$. The total GLS content found in the leaves of the $B$. carinata line (Bc-IASC1) was $10.19 \mu \mathrm{mol} \cdot \mathrm{g}^{-1} \mathrm{DW}$ (equivalent to $101.9 \mu \mathrm{mol}$ per $100 \mathrm{~g}$ fresh weight). Our data for GLS and sinigrin content in B. carinata are in accordance with previous determination in leaves at the same growth stage and resulting sinigrin the major and almost sole GLS presented [13]. 


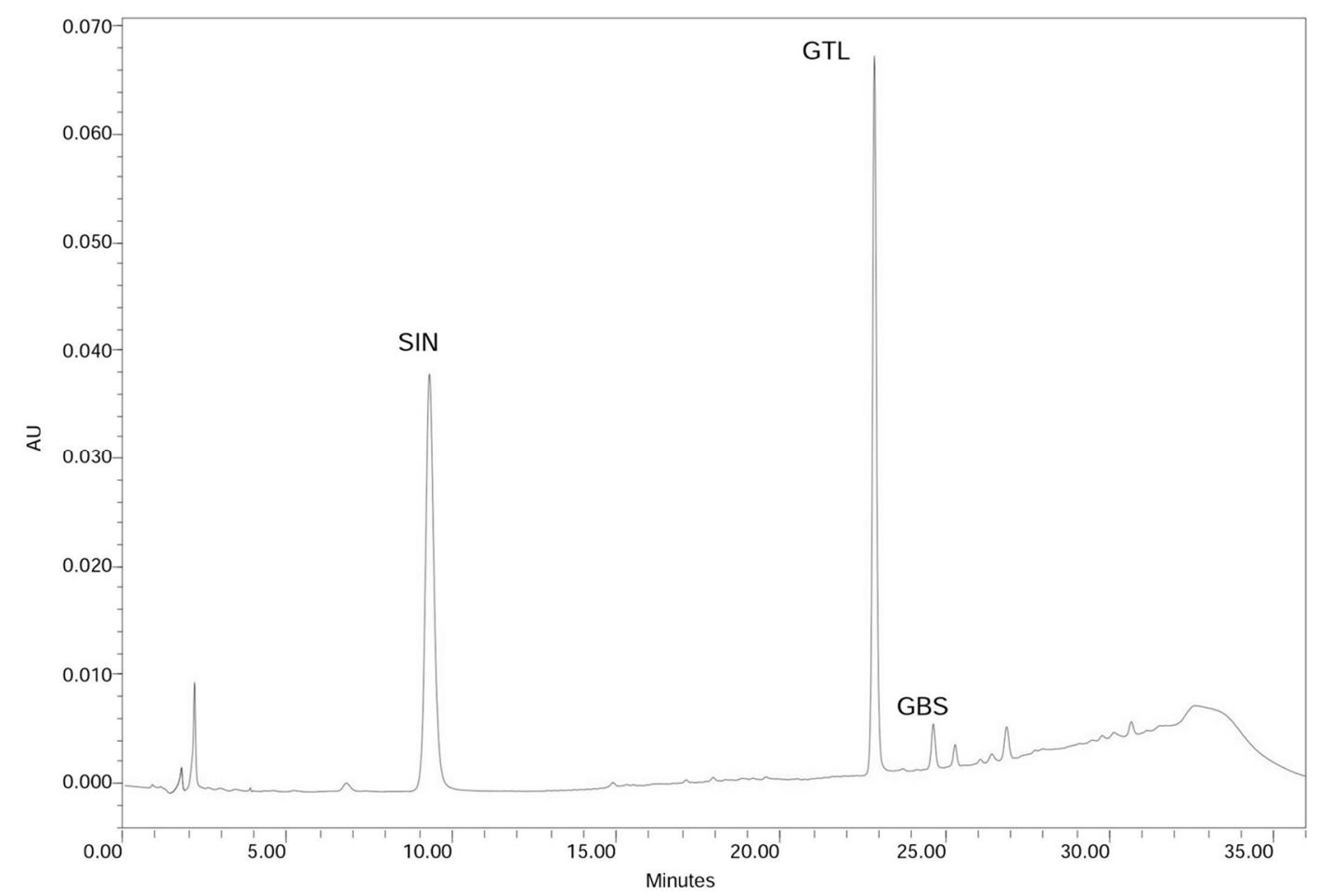

Figure 1. Chromatogram of $B$. carinata leaf samples. Peaks correspond to the identified GLSs: sinigrin (SIN) and glucobrassicin (GBS), and the internal standard glucotropaeolin (GTL).

\subsection{In Vivo Assays}

\subsubsection{Toxicity Assays}

Table 1 shows $B$. carinata plant and sinigrin sample toxicity expressed as percentage of emerged treated adults respect to the negative control emerged adults (survival control corrected). All treatments at all assayed concentrations affected $D$. melanogaster survival with values between $19.33 \%$ and $78.22 \%$, both for sinigrin $1.2 \mathrm{mM}$ in combined and simple treatments respectively. Simple treatments produced a larvae survival around $50 \%\left(\mathrm{LC}_{50}\right)$, which represents normal value in experiments performed to evaluate toxicity levels.

Table 1. Toxicity levels of B. carinata and sinigrin in SMART expressed as Drosophila adults survival after simple and combined treatment (without and with $\mathrm{H}_{2} \mathrm{O}_{2}$ respectively).

\begin{tabular}{|c|c|c|c|c|c|c|c|}
\hline \multicolumn{8}{|c|}{ Toxicity } \\
\hline \multicolumn{8}{|c|}{ Survival a \% Treatments } \\
\hline Controls & Simple & B. carinata $\left(\mathrm{mg} \cdot \mathrm{mL}^{-1}\right)$ & Simple & Combined $^{\mathrm{b}}$ & Sinigrin $\left(\mathbf{m M}^{\mathbf{c}}\right)$ & Simple & Combined $^{b}$ \\
\hline $\mathrm{H}_{2} \mathrm{O}$ & 100 & 1.25 & $55.33 *$ & $37.78 *$ & 0.60 & $56.44 *$ & $25.56 *$ \\
\hline \multirow[t]{3}{*}{$\mathrm{H}_{2} \mathrm{O}_{2}(0.12 \mathrm{M})$} & $37.78 *$ & 2.50 & $53.33 *$ & $30 *$ & 1.20 & $78.22 *$ & $19.33 *$ \\
\hline & & 5.00 & $47.56 *$ & $36.89 *$ & 2.40 & $61.56 *$ & $47.33 *$ \\
\hline & & & & & 4.81 & $76.89 *$ & $60.22 *$ \\
\hline Average & & & 52.07 & 34.89 & & 68.27 & 38.11 \\
\hline
\end{tabular}

a Survival expressed in percentage as emerged adult total of each treatment with respect to $\mathrm{H}_{2} \mathrm{O}$ control emerged adult total; ${ }^{\mathrm{b}}$ Combined treatments using standard medium and $0.12 \mathrm{M} \mathrm{H}_{2} \mathrm{O}_{2} ;{ }^{\mathrm{c}} 1 \mathrm{mM}$ sinigrin $=397.46 \mu \mathrm{g} \cdot \mathrm{mL}^{-1}$ sinigrin; * Asterisks indicate significance levels with respect to the untreated control group $(p \leq 0.05)$. 
Our results are in agreement with those found before [26] in which ITCs were toxic for coleopteran eggs, showing that lethal concentration ( $\mathrm{LC}_{90}$ ) of these compounds were 1.8 to $5.6 \mu \mathrm{g} \cdot \mathrm{mL}^{-1}$ depending on ITC type, being AITC less toxic than aromatic-ITCs.

Regarding B. carinata plant samples, the survival average was $52.07 \%$ and $34.89 \%$ for simple and combined treatments, respectively. This reduction of survival $(\sim 18 \%)$ is explained by the addition of $\mathrm{H}_{2} \mathrm{O}_{2}$ to the medium (combined treatment) as a potent toxic agent. This $\mathrm{H}_{2} \mathrm{O}_{2}$ effect was also observed in sinigrin treatments were survival average was $38.11 \%$ in combined against $68.27 \%$ simple treatments ( $\sim 30 \%$ survival reduction).

In simple treatments, sinigrin showed a less toxic effect than $B$. carinata samples at all tested concentrations. This fact could be explained by the complex composition of plant samples when compared with single compounds. In this sense, B. carinata plant possesses anti-nutrients such as phytates, phenolics, and tannins which can affect individual survival $[3,5]$.

In combined treatments, $B$. carinata addition had no significant effect on $D$. melanogaster survival so that the number of emerged adults was similar to those of positive control $\left(\mathrm{H}_{2} \mathrm{O}_{2}\right.$ treatment survival $=$ $37.78 \%$ ) although some synergistic but not additive effect of $\mathrm{H}_{2} \mathrm{O}_{2}$ and $B$. carinata products is found in concentrations of 2.5 and $5 \mathrm{mg} \cdot \mathrm{mL}^{-1}$. Contrarily, sinigrin addition to the medium counteracted $\mathrm{H}_{2} \mathrm{O}_{2}$ toxicity at the highest assayed concentrations $(2.4$ and $4.81 \mathrm{mM})$ but, this effect of detoxification did not appeared at low sinigrin concentrations (0.6 and 1.2) in which the toxic effect was higher, reducing the number of emerged adults (25.56\% and $19.33 \%$ of survival, respectively).

In general, no dose effect was observed except in sinigrin combined treatments in which the lesser survival percentage (19.33\%) corresponded to a concentration of $1.2 \mathrm{mM}$ and the highest percentage $(60.22 \%)$ to the highest concentration assayed $(4.81 \mathrm{mM})$. Other concentrations could be assayed in order to determine a dose effects in tested samples but they would not be relevant for human consumption.

\subsubsection{Genotoxicity Assays}

Direct studies on the toxicity and genotoxicity of B. carinata fresh plant are not available because the epidemiological data always shows protective anticancer health properties [27]. The present study on the genotoxicity of $B$. carinata is the first that has confirmed the epidemiological references probing that $B$. carinata plant did not exert any DNA damage in the $m w h / f l r$ eukaryotic system of $D$. melanogaster.

Due to the antioxidant capacity of $B$. carinata [28] and sinigrin [29], $\mathrm{H}_{2} \mathrm{O}_{2}$ has been selected as oxygen free radical generator in this work. This compound has been showed as a potent mutagen [30] by producing highly reactive hydroxyl radicals $\left({ }^{\bullet} \mathrm{OH}\right)$. Thus, the present work has tried to prove the antioxidant capacity of tested samples which could act as antimutagens avoiding DNA damage produced by $\mathrm{H}_{2} \mathrm{O}_{2}$.

Table 2 shows the results of $\mathrm{H}_{2} \mathrm{O}_{2}$ genotoxic activity, as a positive control, both in marker-heterozygous and in balancer-heterozygous wings. $\mathrm{H}_{2} \mathrm{O}_{2}$ has been selected as a positive control due to its proved oxidative genotoxic activity in the SMART being able to induce somatic mutation and mitotic recombination [31]. Our results are consistent with this showing that $\mathrm{H}_{2} \mathrm{O}_{2}$ increased small single and total spots. The genotoxic results for $\mathrm{H}_{2} \mathrm{O}_{2}$ validate the assay as an appropriate system for screening mutagens (positive controls as $\mathrm{H}_{2} \mathrm{O}_{2}$ ) and non-mutagens (distilled-sterile water controls or safe plants). 
The genotoxicity results obtained in the SMART of D. melanogaster for B. carinata and sinigrin are summarized in Table 2. No sample was mutagenic at any tested concentration. Contrarily they produce total mutation rates lower than those of the negative control at any dose, with an average of 0.18 and 0.15 spots per wing in the $B$. carinata and sinigrin experiments respectively. In this sense, food metabolism products generate free radicals in cells such as oxygen and nitrogen reactive species [32] which produce mutations. In SMART, these mutations are scored in negative control and they are due to larva feeding of standard Carolina medium. Any addition to this medium can increase (i.e., the mutagen used, $\mathrm{H}_{2} \mathrm{O}_{2}$ ) or decrease this mutation range (free radical scavenger) which is the case of assayed samples, so our plant and molecule samples produce a mutation rate lower than negative control, acting as antimutagens against larva medium.

Table 2. Genotoxicity of $B$. carinata and sinigrin in SMART. Frequencies of mutations (spots/wing) for each category (Small, Large, Twin and Total) obtained in simple treatment.

\begin{tabular}{|c|c|c|c|c|c|}
\hline \multicolumn{6}{|c|}{ Genotoxicity } \\
\hline \multicolumn{6}{|c|}{ Mutation Rate (Spots per Wing) Diagnosis a } \\
\hline Treatment & $\mathrm{N}^{\circ}$ of wings & Small single spots $1-2$ cells; $m=2$ & $\begin{array}{c}\text { Large single } \\
\text { spots }>2 \text { cells; } m=5\end{array}$ & $\begin{array}{c}\text { Twin spots } \\
m=5\end{array}$ & $\begin{array}{c}\text { Total spots } \\
\quad m=2\end{array}$ \\
\hline \multicolumn{6}{|c|}{ Controls } \\
\hline $\mathrm{H}_{2} \mathrm{O}$ & 212 & $0.26(54)$ & $0.04(8)$ & $0.03(5)$ & $0.32(67)$ \\
\hline $\mathrm{H}_{2} \mathrm{O}_{2}(0.12 \mathrm{M})$ & 168 & $0.60(94)+$ & $0.07(11)-$ & $0.06(4)-$ & $0.65(109)+$ \\
\hline \multicolumn{6}{|c|}{ Plant Material: Brassica carinata $\left(\mathrm{mg} \cdot \mathrm{mL}^{-1}\right)$} \\
\hline 1.25 & 40 & $0.01(4)-$ & $0.03(1)-$ & $0.03(1)-$ & $0.15(6)-$ \\
\hline 2.50 & 48 & $0.15(7)-$ & $0.04(2)-$ & $0.02(1)-$ & $0.21(10)-$ \\
\hline 5.00 & 48 & $0.13(6)-$ & $0.02(1)-$ & $0.02(1)-$ & $0.19(8)-$ \\
\hline \multicolumn{6}{|c|}{ Single Compound: Sinigrin $(\mathrm{mM})^{b}$} \\
\hline 0.60 & 40 & $0.18(7)-$ & $0.03(1)-$ & 0 & $0.20(8)-$ \\
\hline 1.20 & 34 & $0.12(4)-$ & $0.03(1)-$ & $0.03(1)-$ & $0.18(6)-$ \\
\hline 2.40 & 36 & $0.08(3)-$ & $0.03(1)-$ & 0 & $0.11(4)-$ \\
\hline 4.81 & 28 & $0.14(4)-$ & 0 & 0 & $0.14(4)-$ \\
\hline
\end{tabular}

${ }^{\text {a }}$ Statistical diagnoses [33,34]: + (positive) and - (negative). Significance levels $\alpha=\beta=0.05$, one-sided test without Bonferroni correction; ${ }^{\mathrm{b}} 1 \mathrm{mM}$ sinigrin $=397.46 \mu \mathrm{g} \cdot \mathrm{mL}^{-1}$ sinigrin.

This non-genotoxic effect found in D. melanogaster are useful data to consider the inclusion of B. carinata in human diet even more than other Brassica spp. more popular and worldwide consumed i.e., broccoli (B. oleracea L. var. italica) which raw, freeze-dried market plants lead to an increase in genotoxicity in this in vivo test [35]. In this sense, some recent studies gave rise to the concern that broccoli and other commercial varieties possess genotoxic activity due to their content in DNA damaging constituents such as certain types of GLSs [6,36]. Contrarily, we have not found this undesirable effect in our tested plant B. carinata, a fact that would reinforce the proposal for using it as a dietary source and makes this species more appropriate for human intake than its close relatives. The different GLS profiles found in Brassica spp. may be the responsible for this apparent discrepancy, as sinigrin is a minor GLS constituent in such a species [37] and contrarily, it is the main GLS in B. carinata.

Our results on the lack of genotoxicity of sinigrin are in concordance with previous studies [38] showing that sinigrin is neither genotoxic nor cytotoxic in the in vitro hamster ovary cell line (CHO) 
system. These authors also showed that AITC are not genotoxic at high cytotoxic doses as opposed to phenethyl-ITCs (breakdown products containing an aromatic functional group). Nevertheless, sinigrin induced chromosome aberrations but not sister chromatid exchanges at concentrations of $2 \mathrm{mg} \cdot \mathrm{mL}^{-1}$. On the other hand, toxicity tests performed in the nematode Caenorhabditis elegans [14] concluded that sinigrin is non-toxic up to the concentration $80 \mathrm{~g} \cdot \mathrm{L}^{-1}$ and the addition of myrosinase increased sinigrin toxicity $\left(\mathrm{LC}_{50}=0.5 \mathrm{~g} \cdot \mathrm{L}^{-1}\right)$. The same experiment performed directly with AITC resulted in a lethal concentration value of $0.04 \mathrm{~g} \cdot \mathrm{L}^{-1}$.

\subsubsection{Antigenotoxicity Assays}

The results obtained for antigenotoxicity assays are a contribution to the health properties of B. carinata and sinigrin in DNA protection. Analysed samples showed that this plant behaves as a desmutagen by reducing the apparition of mutations in comparison with negative control. Table 3 show the percentage of inhibition of $B$. carinata and sinigrin (respectively) when are assayed against $\mathrm{H}_{2} \mathrm{O}_{2}$. As expected, the addition of plant/compound samples to the fly food produced antimutagenic effects.

Table 3. Antigenotoxicity of $B$. carinata and sinigrin in SMART. Frequencies of mutations (spots/wing) for each category (Small, Large, Twin and Total) obtained in combined treatments.

\begin{tabular}{|c|c|c|c|c|c|}
\hline \multicolumn{6}{|c|}{ Antigenotoxicity } \\
\hline \multicolumn{6}{|c|}{ Mutation Rate (Spots per Wing) Diagnosis ${ }^{a}$} \\
\hline Treatment & $\mathrm{N}^{\circ}$ of wings & $\begin{array}{c}\text { Small single spots } \\
1-2 \text { cells; } m=2\end{array}$ & $\begin{array}{c}\text { Large single } \\
\text { spots }>2 \text { cells } m=5\end{array}$ & $\begin{array}{c}\text { Twin spots } \\
m=5\end{array}$ & $\begin{array}{c}\text { Total spots } \\
m=2\end{array}$ \\
\hline \multicolumn{6}{|c|}{ Controls } \\
\hline $\mathrm{H}_{2} \mathrm{O}$ & 212 & $0.26(54)$ & $0.04(8)$ & $0.03(5)$ & $0.32(67)$ \\
\hline $\mathrm{H}_{2} \mathrm{O}_{2}(0.12 \mathrm{M})$ & 168 & $0.60(94)+$ & $0.07(11)-$ & $0.06(4)-$ & $0.65(109)+$ \\
\hline \multicolumn{6}{|c|}{ Plant Material: Brassica carinata $\left(\mathrm{mg} \cdot \mathrm{mL}^{-1}\right)$} \\
\hline 1.25 & 40 & $0.11(4)-$ & $0.03(1)-$ & 0 & $0.14(5)-$ \\
\hline 2.50 & 48 & $0.25(7)-$ & $0.04(1)-$ & 0 & $0.29(8)-$ \\
\hline 5.00 & 48 & $0.27(8)-$ & $0.03(1)$ & 0 & $0.30(9)-$ \\
\hline \multicolumn{6}{|c|}{ Single Compound: Sinigrin $(\mathrm{mM})^{b}$} \\
\hline 0.60 & 40 & $0.19(6)-$ & 0 & 0 & $0.19(6)-$ \\
\hline 1.20 & 34 & $0.20(4)-$ & 0 & 0 & $0.20(4)-$ \\
\hline 2.40 & 36 & $0.25(1)-$ & 0 & 0 & $0.25(1)-$ \\
\hline 4.81 & 28 & $0.10(1)-$ & 0 & 0 & $0.10(1)-$ \\
\hline
\end{tabular}

a Statistical diagnoses [33,34]: + (positive) and - (negative). Significance levels $\alpha=\beta=0.05$, one-sided test without Bonferroni correction; ${ }^{\mathrm{b}} 1 \mathrm{mM}$ sinigrin $=397.46 \mu \mathrm{g} \cdot \mathrm{mL}^{-1}$ sinigrin.

Both samples showed a high desmutagenic and recombinogenic potency always producing the total mutation rates below the negative control values (Table 3). An inverse dose effect was also observed for B. carinata and sinigrin samples so, the lowest concentrations assayed for plant samples were more antigenotoxic than those of higher $(78.46 \%$ clone inhibition) but, for sinigrin samples this was reversed: the highest antigenotoxic effect corresponded to a sinigrin concentration of $4.81 \mathrm{mM}$ with a percentage of inhibition of clone formation of $84.61 \%$ (Figure 2). This healthier beneficial effect of sinigrin at higher concentrations is in agreement with the survival and genotoxicity experiments in which its positive effect 
was superior to those of $B$. carinata. Unlike sinigrin, the effects of $B$. carinata samples are the result of a complex mixture with a large number of different compounds with different effects. Further studies will be required in order to elucidate the underlying B. carinata and sinigrin protective mechanism. Nevertheless, B. carinata antimutagenic properties have been demonstrated.
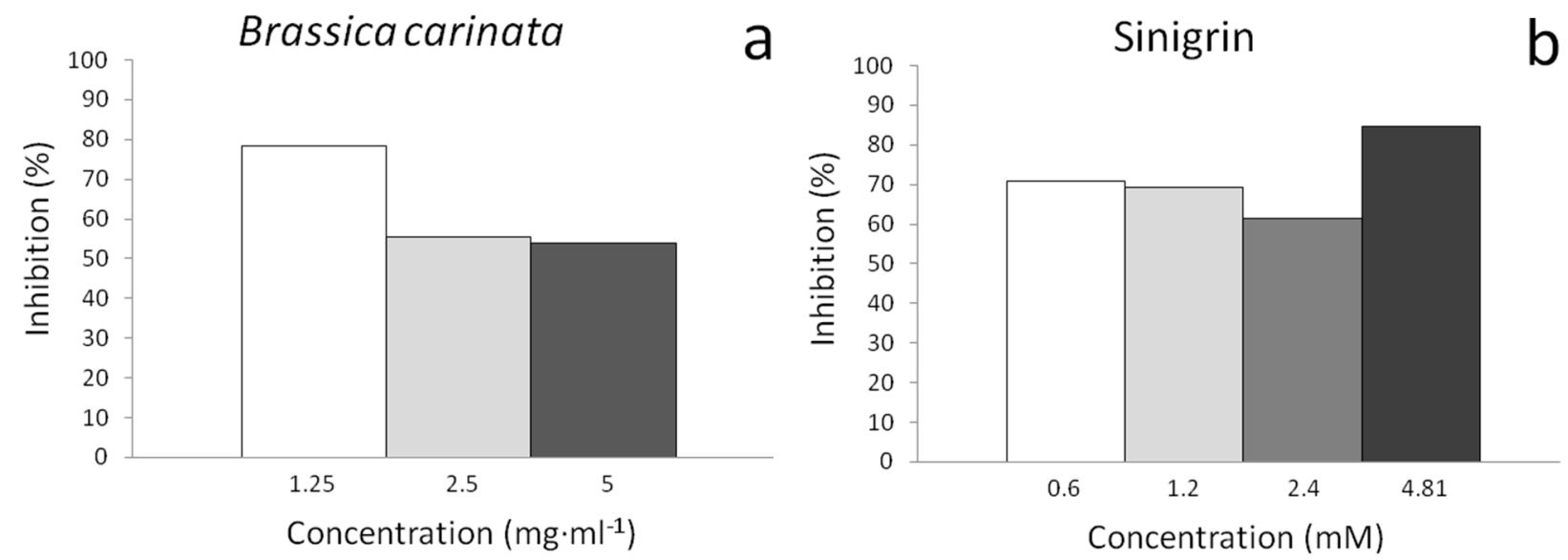

Figure 2. Inhibition effects of: (a) $B$. carinata and (b) sinigrin, against $\mathrm{H}_{2} \mathrm{O}_{2}(0.12 \mathrm{mM})$ as genetic damage inductor. Correspondence: $1 \mathrm{mM}$ sinigrin $=397.46 \mu \mathrm{g} \cdot \mathrm{mL}^{-1}$ sinigrin.

Other Brassica spp. like B. oleracea L. var. acephala (kale) present the same effect. The leaf extract of these plants has neither genotoxic nor clastogenic activity in cells of mice [39] but a strong antigenotoxic effect. This Brassica variety presents a similar GLS profile to B. carinata, both with sinigrin as major leaf GLS [40] and best candidate responsible of this DNA protective effect.

\subsection{In Vitro Assays}

The promyelocytic cell line HL60 has been selected as a model on a big variety of substances candidates to be used as anticarcinogens and has proved to be a robust test system for pilot screening experiments [41]. In the case of GLS breakdown products, different HL60 cell lines have been used to prove the anticarcinogenic properties of diverse ITC groups resulting AITC the most effective arresting cell cycle [42]. Now, we have used this system to determine the antitumor properties of the plant $B$. carinata and specifically, its major GLS sinigrin by measuring the relative inhibitory capacity of tumor growing in HL60 cells. Our experiments have evidenced that B. carinata plant possesses antiproliferative properties and highlight the use of this plant in cancer chemoprevention.

The results on Figure 3 represent the relative growing rate of HL60 cultures (expressed as cell survival) with different concentrations of $B$. carinata and sinigrin respect to their concurrent control cultures. B. carinata results showed a dose-response curve with a high tumoricide activity in HL60 cells ( $\mathrm{IC}_{50}$ value of $0.28 \mathrm{mg} \cdot \mathrm{mL}^{-1}$ ). However, the antigenotoxic potency of sinigrin did not correlate with its null antiproliferative activity. The reason of this lack of cytotoxicity resides in the metabolic process by which GLSs produce their anticarcinogenic effect. In this sense, the fact that GLS sinigrin only acts as a cytotoxic agent when is hydrolysed by myrosinase enzyme revealing this mechanism. 


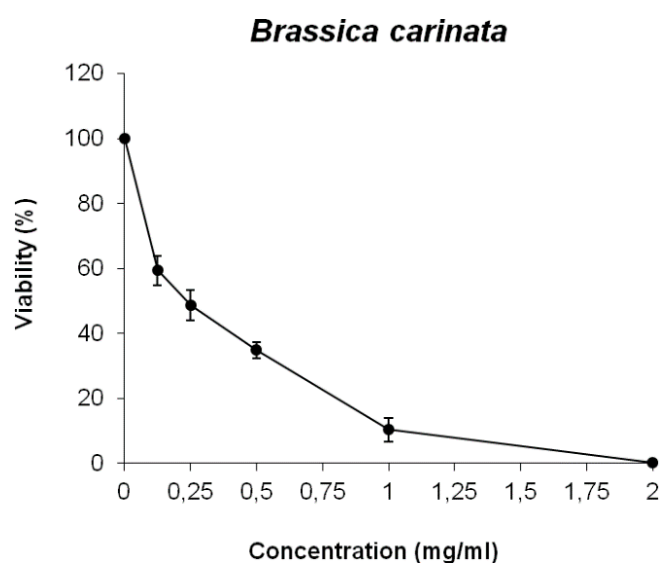

(a)

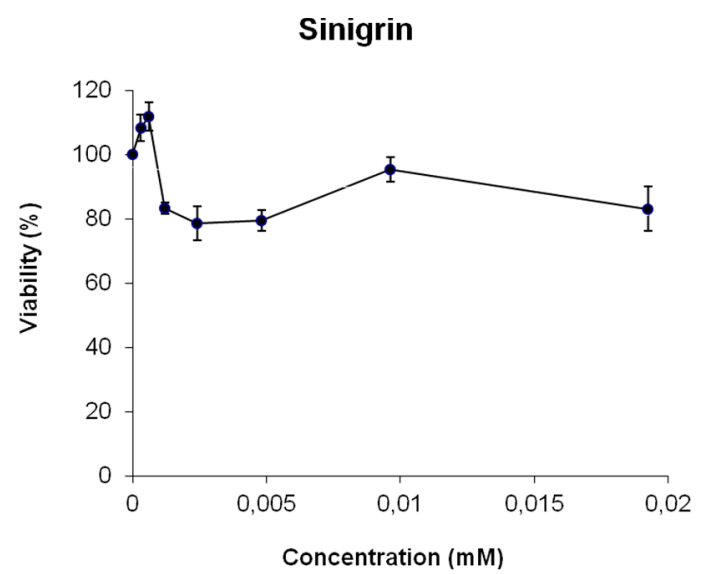

(b)

Sinigrin + Myrosinase

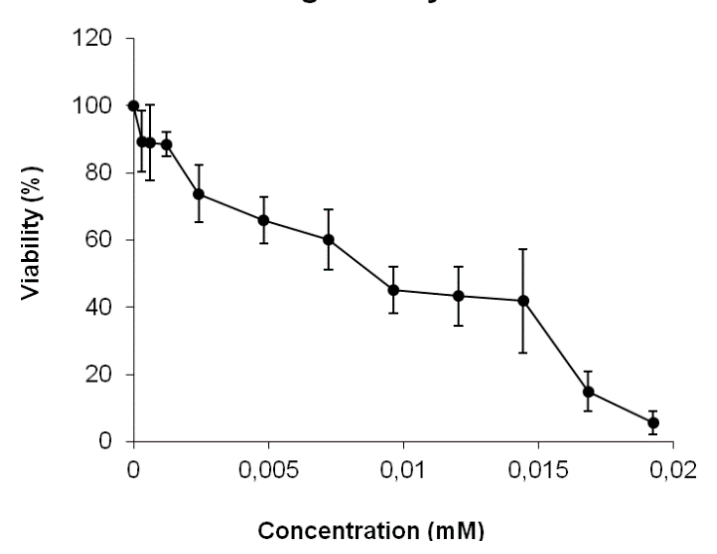

(c)

Figure 3. Survival of HL60 cultures treated with different concentrations of: (a) B. carinata; (b) sinigrin; (c) sinigrin + myrosinase. Curves are plotted as percentages with respect to the control counted from at least three independent experiments (mean $\pm \mathrm{SD}$ ). Correspondence: $1 \mathrm{mM}$ sinigrin $=397.46 \mu \mathrm{g} \cdot \mathrm{mL}^{-1}$ sinigrin.

Under natural conditions, GLSs and myrosinases are stored in separate compartments in plant tissues and different process like feeding by insect, animals or, in human case, food processing can put them into contact. Then, plant tissue disruption induce bioactivation of GLSs, putting myrosinases and their GLS substrates into contact, and GLS hydrolysis results in the formation of their biologically active products. To achieve this, our experiments performed using $D$. melanogaster individuals did not require more sample process that adds directly the plant or the bioactive compound to food waiting for their oral ingestion because of the presence of myrosinase in plant treatments or because myrosinase activity occurs normally during digestion and in the colon by microbial activity (sinigrin treatments) [6]. Contrarily, cytotoxicity assays with HL60 cell lines required the addition of an external myrosinase to sinigrin solution as a necessary step in order to produce its hydrolysis and antiproliferative activity (Figure 3C) because the addition of single sinigrin to cell medium did not produce expected effect by reducing cell proliferation (Figure 3B). So that, sinigrin produced antiproliferative activity in HL60 culture only after its hydrolysis by the enzyme myrosinase (hydrolysed sinigrin $\mathrm{IC}_{50}=2.71 \mu \mathrm{M}$ ). In this sense, the presence of constitutive myrosinase in B. carinata plant samples justifies the antiproliferative 
activity found in the present research (Figure 3A). This activity also shows that lyophilized plants do not affect myrosinase function and conserved it intact, unlike other processing methods [6] although the combined treatment of plant and myrosinase has not been assayed. As a dependent temperature enzyme, myrosinase activity is favoured by low heat process up to $30{ }^{\circ} \mathrm{C}$ (in vitro HL60 experiment temperature) [43], facilitating the total GLS hydrolysis and the apparition of their healthy properties. Authors suggest that the human body temperature should be high enough for a proper GLSs digestion and nutrient intake. In addition, another plant proteins and active compounds will be protected to maintain intact plant health effects.

Others authors have found the same chemopreventive effect of Brassica spp. in certain tumor types by ceasing culture growth due to GLSs hydrolyzed into ITCs [16,44,45]. All these research has focused on the anti-carcinogenic activity of GLSs and ITCs as responsible compounds and that their intake and posterior digestion allow this process. In this sense, other authors [46] founded that sinigrin is able to inhibit induced hepatocarcinogenesis in rats when it is orally given in a diet containing $1.2 \mathrm{mg}$ sinigrin $\cdot \mathrm{mg}^{-1}$ food. This antiproliferative activity has also been shown in human in vitro models as HT29 colorectal tumor cells [47] and SK-Hep1 human hepatoma cells [48]. Our results are consistent with these researches because sinigrin is not cytotoxic but its hydrolysis products are. Further studies using each individual breakdown product of sinigrin can be conducted to elucidate the process whereby B. carinata induces the antitumor activity.

In conclusion, our results not only support the health benefits for humans of $B$. carinata plant in daily intake as a recommended vegetable to include in human diet, but also present sinigrin as precursor of AITCs the bioactive chemicals responsible of this effect and break-down products of sinigrin hydrolysis by myrosinase enzyme.

\section{Experimental Section}

\subsection{Plant Material and Chemicals}

The analysed genotype of Ethiopian mustard (Brassica carinata A. Braun) Bc-IASC1 is part of a Brassica germplasm collection of the Institute of Sustainable Agriculture (IAS-CSIC, Córdoba, Spain). This line was selected because of its drought resistance and good agronomic performance in previous studies carried out under rainfed conditions typical of the Mediterranean ecosystem [11]. Plants were cultivated in an experimental orchard at the IAS $\left(37^{\circ} 52^{\prime} \mathrm{N} 4^{\circ} 46^{\prime} \mathrm{W}\right)$ wherein the climate is typically Mediterranean, with an average annual rainfall of $650 \mathrm{~mm}$. The soil is deep and sandy-loam, classified as a Typic Xerofluvent. Leaves of five plants were harvested when they reached the stem elongation stage corresponding to code 49 of the BBCH scale [49], weighed, frozen $\left(24 \mathrm{~h}\right.$ at $\left.-80{ }^{\circ} \mathrm{C}\right)$ and lyophilized with a freeze-drier Telstar model Cryodos-50 (Telstar, Terrasa, Spain). After lyophilisation, dry material was weighed again, grounded in a Janke and Kunkel Model A10 mill (IKA-Labortechnik, Staufen, Germany) for about $20 \mathrm{~s}$, mixed and conserved at room temperature and darkness to preserve their properties until use.

Sinigrin $\left(\mathrm{C}_{10} \mathrm{H}_{16} \mathrm{KNO}_{9} \mathrm{~S}_{2} \cdot \mathrm{H}_{2} \mathrm{O}\right)$ and myrosinase (EC 3.2.1.147) were purchased from Sigma-Aldrich (St. Louis, MO, USA) and glucotropaeolin $\left(\mathrm{C}_{14} \mathrm{H}_{18} \mathrm{KNO}_{9} \mathrm{~S}_{2}\right)$ from Phytoplan (www.phytoplan.de; Heidelberg, Germany). 


\subsection{HPLC}

The GLS composition of $B$. carinata samples was determined by High Performance Liquid Chromatography (HPLC) [50]. About $100 \mathrm{mg}$ of DW of sample was weighed and a two-step glucosinolate extraction was carried out in a water bath at $75{ }^{\circ} \mathrm{C}$ to inactivate myrosinase. In the first step the sample was heated for $15 \mathrm{~min}$ in $2.5 \mathrm{~mL} 70 \%$ aqueous methanol and $200 \mu \mathrm{L} 10 \mathrm{mM}$ glucotropaeolin (benzyl-GLS) as internal standard. A second extraction was applied after centrifugation (5 min, $5000 \mathrm{~g}$ ) by using $2 \mathrm{~mL}$ of $70 \%$ aqueous methanol. One $\mathrm{mL}$ of the combined glucosinolate extracts was pipette onto the top of an ion-exchange column containing $1 \mathrm{~mL}$ Sephadex DEAE-A25 in the formiate form. Desulphation was carried out by the addition of $75 \mu \mathrm{L}$ of purified sulphatase (E.C. 3.1.6.1, type H-1 from Helix pomatia) (Sigma-Aldrich, St. Louis, MO, USA) solution. Sulphatase was purified according to the ISO protocol (ISO 9167-1, 1992) [51]. Desulphated glucosinolates were eluted with $2.5 \mathrm{~mL}$ $(0.5 \mathrm{~mL} \times 5)$ Milli-Q (Millipore, Merck, Damstadt, Germany) ultra-pure water and analysed with a Model 600 HPLC instrument (Waters, Milford, MA, USA) equipped with a Model 486 UV tunable absorbance detector (Waters) at a wavelength of $229 \mathrm{~nm}$. Separation was carried out by using a Lichrospher 100 RP-18 in Lichrocart 125-4 column, $5 \mu \mathrm{m}$ particle size (Merck, Damstadt, Germany). HPLC solvents and gradient were according to the ISO protocol (ISO 9167-1, 1992). The HPLC chromatogram was compared to the desulpho-glucosinolate profile of three certified reference materials recommended by U.E. and ISO (CRMs 190, 366 and 367) analysed under the same conditions except for the use of sinigrin (2-propenyl-GLS) as internal standard [51]. The amount of each individual glucosinolate present in the sample was calculated by mean of the internal standard, and expressed as $\mu \mathrm{mol} \cdot \mathrm{g}^{-1}$ of DW. Data were corrected for UV response factors for different types of glucosinolates (ISO 9167-1, 1992). Data results were analyzed using the work station Waters Millenium 32 Chromatography Manager Software.

\subsection{Fly Stocks and Crosses}

The genotoxic and antigenotoxic activity of lyophilized leaves of B. carinata and sinigrin were evaluated by the Drosophila Somatic Mutation and Recombination Test (SMART) [52]. Drosophila is a holometabolous animal which in vivo experiments permit to make analogies with humans due to the high percentage of homologue genes in common with human [53]. We have selected the D. melanogaster SMART as a well-known eukaryotic assay that represents a rapid and economic way to evaluate the genotoxicity and antigenotoxicity of single compounds and complex mixtures [54]. Both characteristics make this test an optimal protocol in order to test molecules and complex mixtures with health benefices for humans. Two different $D$. melanogaster strains carrying visible wing genetic markers on the left arm of chromosome 3 were used: the flare $(f l r)$ strain $f l r^{3} / \ln (3 L R) T M 3, B d^{s}$ and the multiple wing-hair $(m w h)$ strain $m w h / m w h$ [55]. These markers were selected due to their position in the Drosophila genome, covering a wide portion of one of their four chromosomes. Specifically, they affect the wing imaginal disks which present more cells with a uniform growth during larvae development than other Drosophila imaginal disks. This fact makes possible to detect easily a high number of mutations, somatic recombinations and disjunctions produced in the Drosophila DNA during all treatment periods by wing microscopic observation. In this sense, these markers are present in other genetic background (strains) but crosses produce mutations with a basal mutation rate too high and disturbing hair anomalous pattems. The 
marker flare $\left(f l r^{3}, 3\right.$ 38.3) is a recessive mutation which produces individual wing hairs that are malformed. The $f l r^{3}$ allele is a zygotic recessive lethal, which is maintained in the strain over the balancer chromosome TM3 (TM3, $B d^{S}$ : Third Multiple 3, Beaded-Serrate). The marker multiple wing hairs ( $m w h$, 3_0.3) is a recessive mutation that is viable in homozygous flies, producing multiple hairs per cell instead of the wild type single-hair trichome. Two types of crosses were used: the standard cross with $f l r^{3} / T M 3$, $B d^{S}$ females mated to $m w h / m w h$ males and the reciprocal cross.

\subsection{Toxicity, Genotoxicity and Antigenotoxicity Studies}

Hybrid eggs from crossing optimally fertile flies were collected over an 8-h period. Emerged larvae, $72 \pm 4 \mathrm{~h}$ later, were cleaned up from remaining feeding medium, using sterile distilled water, and subsequently were transferred into treatment vials. These vials contained tested conditions which consisted of $0.85 \mathrm{~g}$ of Drosophila Instant Medium (Formula 4-24, Carolina Biological Supply, Burlington, NC, USA) wetted with $4 \mathrm{~mL}$ of a mixture of distilled-sterile water and the appropriate concentration of lyophilized plant or the single compound sinigrin.

Genotoxicity/antigenotoxicity tests were performed following the standard protocol [52]. Antigenotoxicity tests were carried out by mixing the genotoxin hydrogen peroxide $\left(\mathrm{H}_{2} \mathrm{O}_{2}\right.$, Sigma-Aldrich) with the plant or single compound in appropriate concentrations.

The groups consisting of approximately 100 larvae each were: (i) negative control (distilled water); (ii) mutagenic positive control $\left(\mathrm{H}_{2} \mathrm{O}_{2} 0.12 \mathrm{M}\right.$ ); (iii) 3 vials with increasing concentrations of $B$. carinata $\left(1.25,2.5\right.$, and $\left.5 \mathrm{mg} \cdot \mathrm{mL}^{-1}\right)$; and (iv) 4 vials with increasing concentrations of sinigrin $(0.6,1.2,2.4$ and $4.8 \mathrm{mM}$ ). Sinigrin concentrations were chosen on the basis of the sinigrin content of the $B$. carinata sample used in this study.

Larvae were fed on both treated and control mediums until pupation (about $48 \mathrm{~h}$ ). After emergence, resulting adult flies were collected from the treatment vials, sacrificed under $\mathrm{CO}_{2}$ narcotization and stored in a $70 \%$ ethanol solution in sterile water.

Transheterozygous wings ( $\left.m w h \mathrm{flr}^{+} / m w h^{+} f l r^{3}\right)$ were mounted and wing hair mutations (spots) were scored. Both dorsal and ventral surfaces of the wings containing 22,000 cells were screened under a photonic microscope (Nikon, Amsterdam, Netherlands) at 400× magnification for the occurrence of individual spots ( $m w h$ or $f l r$ phenotype) or twin spots ( $m w h$ clone adjacent to $f l r$ clone). Small individual spots with one or two cells exhibiting the $m w h$ phenotype corresponded to gene mutation and somatic recombination between the two marker genes occurring during the last mitotic rounds in the imaginal discs of the larvae. Large individual spots with three or more cells showing $m w h$ or flr phenotypes corresponded to mutational events occurring earlier during larvae development. Twin spots with two juxtaposed clones corresponded uniquely to recombination events between the $f l r^{3}$ gene and the centromere.

\subsection{Cell Culture and Treatments}

The human leukaemia cell line HL60 (promyelocitic cells) was supplied by Dr. José M. Villalba Montoro (Department of Cell Biology, University of Cordoba, Cordoba, Spain). HL60 cells were routinely grown in suspension in RPMI-1640 medium (ThermoFisher, Invitrogen, Madrid, Spain). This medium was supplemented with an antibiotic antimycotic solution 100× (A5955, Sigma-Aldrich, St. Louis, MO, USA) L-glutamine $200 \mathrm{mM}$ (Sigma-Aldrich) and 10\% heat-inactivated foetal bovine serum (Linus) in a 
$5 \% \mathrm{CO}_{2}$ humidified atmosphere at $37^{\circ} \mathrm{C}$ using a $\mathrm{CO}_{2}$ Incubator (Shellab, Cornelious, OR, USA). HL60 cells were subcultured every 2-3 days to maintain logarithmic growth and they were allowed to grow for $48 \mathrm{~h}$ before use. Cultures were plated at a density of $12.5 \times 104$ cells $\cdot \mathrm{mL}^{-1}$ in $40 \mathrm{~mL}$ culture bottles $\left(25 \mathrm{~cm}^{2}\right)$.

The cytotoxic activity of the treatments was measured as growing inhibition or decreased viability on the human promyelocytic leukaemia cell line HL60. For measuring the cytotoxic effect of tested samples a general protocol [56] was modified by us. Cells were placed in 12 well culture plates $\left(1 \times 10^{5}\right.$ cells $\cdot \mathrm{mL}^{-1}$; final volume per well was $\left.2 \mathrm{~mL}\right)$ and treated with different filtered (Millipore "non-pyrogenic", "sterile-R", $0.2 \mu \mathrm{m}$ filter) RPMI solutions with the selected concentrations of B. carinata $\left(0.125,0.25,0.5,1\right.$ and $\left.2 \mathrm{mg} \cdot \mathrm{mL}^{-1}\right)$, sinigrin $(0.3,0.6,1.2,2.4,4.8,9.6$ and, $19.25 \mathrm{mM})$ and the mixture of sinigrin $(0.3,0.6,1.2,2.4,4.8,7.2,9.6,12,14.4,16.8$ and $19.25 \mathrm{mM})+$ myrosinase. Cells were counted each $24 \mathrm{~h}$ for 7 days. Tested concentrations were calculated based on those used for genotoxicity assays to equal the range of tested doses. The myrosinase-catalysed hydrolysis products of sinigrin solution were prepared dissolving the intact sinigrin in RPMI medium $\left(3.2 \mathrm{mg} \cdot \mathrm{mL}^{-1}\right)$ in a volume of $5 \mathrm{~mL}$ (stock solution). After total dissolution, myrosinase enzyme was added at a concentration of $5 \mathrm{mM}$. This stock solution (sinigrin + myrosinase) was homogenized by shaking and incubated at $30{ }^{\circ} \mathrm{C}$ for $30 \mathrm{~min}$ to activate the enzyme and produce sinigrin hydrolysis [56]. Then, sinigrin hydrolysed solution was diluted to the desired concentrations and applied to cell cultures. An enzyme control solution (without sinigrin) containing only RPMI medium with myrosinase was prepared and used in the same conditions in order to verify that enzyme do not affect cells when compared with negative control (untreated culture).

\section{Cell Viability Assay}

Cell viability was determined by the Trypan Blue dye exclusion test (Sigma-Aldrich). Cells were counted by adding an aliquot of $10 \mu \mathrm{L}$ of the culture to $10 \mu \mathrm{L}$ of the Trypan Blue dye solution. The mix was counted under a light inverted microscope (AE30/31, Motic Spain SLU, Barcelona, Spain) using a Neubauer chamber. Non-viable cells stained purple-violet, whereas viable cells remained unstained.

\subsection{Statistical Analysis}

Toxicity (T) was determined as percentage of survival adults with respect to 450 untreated $72 \mathrm{~h}$ old larvae from three independent experiments [31]:

$\mathrm{T}=\left(\mathrm{N}^{\circ}\right.$ of emerging individuals in treatment $/ \mathrm{N}^{\circ}$ of emerging individuals in the negative control) $\times 100$

For the evaluation of genotoxic effects, the frequencies of spots per fly of each treated series were compared to the concurrent negative control for each class of mutational clone. A multiple-decision procedure was used to categorize results as positive, positive, inconclusive, or negative [33]. Statistical analyses were carried out for single (a small single spot corresponding to one or two cells exhibiting the $m w h$ phenotype), large (a large single spot corresponding to three or more cells showing $m w h$ or $f l r^{3}$ phenotypes), twin (a large single spot corresponding to three or more cells showing $m w h$ or $f l r^{3}$ phenotypes) and total number of spots recovered. Inconclusive and positive data were evaluated by the 
non-parametric $U$ test of Mann, Whitney and Wilcoxon [34]. The inhibition percentage (IP) was calculated as follows [57]:

$$
\mathrm{IP}=(\text { genotoxin alone }- \text { sample }+ \text { genotoxin }) \times 100 /(\text { genotoxin alone })
$$

For the evaluation of cytotoxic effects, after each culture incubation period, a growth curve was established and $\mathrm{IC}_{50}$ values (concentration of tested compound causing $50 \%$ inhibition of cell growth) were estimated. Viability curves of leukaemia cells were expressed as percentage of survival with respect to controls at $72 \mathrm{~h}$ of growth and plotted as mean viability \pm standard error of at least three independent replicas for each treatment and concentration. Statistical analyses were performed using a Microsoft 2007 Excel spreadsheet. The non-parametric U test of Mann, Whitney and Wilcoxon were assessed with the SPSS Statistic 17.0 software (SPSS, Inc., Chicago, IL, USA).

\section{Acknowledgments}

We are grateful to Gómez (Department of Cell Biology, University of Córdoba, Córdoba, Spain) for HL60 line cell supply. The authors thank the Andalusian Government, Research Projects: 6761, AM46/04 and A55/02 for financial support.

\section{Author Contributions}

Authors who: (1) Conceived and designed the experiments: A.H.-B., A.A.-M.; (2) Performed the experiments: M.-D.L.-B., I.T., S.O.-C.; (3) Analyzed the data: M.-D.L.-B., A.A.-M., A.M.-S.; (4) Contributed reagents/materials/analysis tools: A.H.-B., A.A.-M. (5) Wrote the paper: M.-D.L.-B., A.A.-M., A.H.-B. All authors have read and approved the final manuscript.

\section{Conflicts of Interest}

The authors declare no conflict of interest.

\section{References}

1. Herr, I.; Buchler, M.W. Dietary constituents of broccoli and other cruciferous vegetables: Implications for prevention and therapy of cancer. Cancer Treat. Rev. 2010, 36, 377-383.

2. Manchali, S.; Murthy, K.N.C.; Patil, B.S. Crucial facts about health benefits of popular cruciferous vegetables. J. Funct. Foods 2012, 4, 94-106.

3. Jahgangir, M.J.; Kim, H.K.; Choi, Y.H.; Verpoorte, R. Health-affecting compounds in Brassicaceae. Compr. Rev. Food Sci. Food Saf. 2009, 8, 31-34.

4. Redovniković, I.R.; Glivetić, T.; Delonga, K.; Vorkapic-Furač, J. Glucosinolates and their potential role in plant. Period. Biol. 2008, 110, 297-309.

5. Antonious, G.F.; Bomford, M.; Vincelli, P. Screening Brassica species for glucosinolate content. J. Environ. Sci. Health Part B 2009, 44, 311-316.

6. Latté, K.P.; Appel, K.E.; Lampen, A. Health benefits and possible risks of broccoli-A review. Food Chem. Toxicol. 2011, 49, 3287-3309. 
7. Zukalová, H.; Vašák, J. The role and effect of glucosinolates of Brassica species-A review. Rostl. Vyroba 2002, 48, 175-180.

8. Schippers, R.R. African Indigenous Vegetables: An Overview of the Cultivated Species; University of Greenwich, Natural Resources Institute: London, UK, 2000.

9. Tadelle, D.; Alemu, Y.; Moges, H.M.; Fasil, K. Effect of Level of Rapeseed (Brassica carinata) Cake in Rations on Broiler Performance. Livest. Res. Rural Dev. 2003, 15; Available online: http://www.lrrd.org/lrrd15/4/tade154.htm (accessed on 25 June 2015)

10. Taylor, D.C.; Falk, K.C.; Palmer, C.D.; Hammerlindl, J.; Babic, V.; Mietkiewska, E.; Jadhav, A.; Marillia, E.F.; Francis, T.; Hoffman, T.; et al. Brassica carinata-A new molecular farming platform for delivering bio-industrial oil feedstocks: Case studies of genetic modifications to improve very long-chain fatty acid and oil content in seeds. Biofuels Bioprod. Biorefin. 2010, 4, 538-561.

11. De Haro, A.; Domínguez, J.; García, R.; Muñoz, J.; Fernández-Martínez, J.M. Registration of six Ethiopian mustard germplasm lines. Crop Sci. 1998, 38, 558-559.

12. Warwick, S.I.; Gugel, R.K.; McDonald, T.; Falk, K.C. Genetic variation of Ethiopian mustard (Brassica carinata A. Braun) germplasm in western Canada. Genet. Resour. Crop Evol. 2006, 53, 297-312.

13. Bellostas, N.; Sørensen, J.C.; Sørensen, H. Profiling glucosinolates in vegetative and reproductive tissues of four Brassica species of the U-triangle for their biofumigation potential. J. Sci. Food Agric. 2007, 87, 1586-1594.

14. Donkin, S.G.; Eiteman, M.A.; Williams, P.L. Toxicity of glucosinolates and their enzymatic decomposition products to Caenorhabditis elegans. J. Nematol. 1995, 27, 258-262.

15. Martínez-Ballesta, M.C.; Muries, B.; Moreno, D.A.; Dominguez-Perles, R.; García-Viguera, C.; Carvajal, M. Involvement of a glucosinolate (sinigrin) in the regulation of water transport in Brassica oleracea grown under salt stress. Physiol. Plant 2014, 150, 145-160.

16. Hwang, E.S.; Lee, H.J. Induction of quinone reductase by allylisothiocyanate (AITC) and the $\mathrm{N}$-acetylcysteine conjugate of AITC in Hepalc1c7 mouse hepatoma cells. BioFactors 2006, 26, 7-15.

17. Zhang, Y. Allyl isothiocyanates as a cancer chemopreventive phytochemical. Mol. Nutr. Food Res. 2010, 54, 127-135.

18. Zhang, Y.; Talalay, P. Anticarcinogenic activities of organic isothiocyanates: Chemistry and mechanisms. Cancer Res. 1994, 54, 1976s-1981s.

19. Lamy, E.; Schmitz, S.; Krumbein, A.; Mersch-Sundermann, V. Isothiocyanate-containing mustard protects human cells against genotoxins in vitro and in vivo. Mutat. Res. Genet. Toxicol. Environ. Mutagen. 2011, 726, 146-150.

20. Keck, A.S.; Finley, J.W. Cruciferous Vegetables: Cancer protective mechanisms of glucosinolate hydrolysis products and selenium. Integr. Cancer Ther. 2004, 3, 5-12.

21. USDA. Vegetables. Available online: http://www.choosemyplate.gov/food-groups/vegetables.html (accessed on 25 June 2015).

22. Agudo, A.; Ibanez, R.; Amiano, P.; Ardanaz, E.; Barricarte, A.; Berenguer, A.; Dolores, C.M.; Dorronsoro, M.; Jakszyn, P.; Larranaga, N.; et al. Consumption of cruciferous vegetables and glucosinolates in a Spanish adult population. Eur. J. Clin. Nutr. 2008, 62, 324-331. 
23. Spherix. Generally Recognized as Safe (GRAS) Notification for the Use of Aqueous Broccoli Seed Extract Powder in Food. Available online: http:/www.fda.gov/ucm/groups/fdagov-public/ @ffdagov-foods-gen/documents/document/ucm388588.pdf (accessed on 25 June 2015).

24. Sang, J.H.; King, R.C. Nutritional requirements of axenically cultured Drosophila melanogaster adults. J. Exp. Biol. 1961, 38, 793-809.

25. Miller, R.S.; Thomas, J.L. The effects of larval crowding and body size on the longevity of adult Drosophila melanogaster. Ecology 1958, 39, 118-125.

26. Borek, V.; Elberson, L.R.; McCaffrey, J.P.; Morra, M.J. Toxicity of aliphatic and aromatic isothiocyanates to eggs of the black vine weevil (Coleoptera: Curculionidae). J. Econ. Entomol. 1995, 88, 1192-1196.

27. Verhoeven, D.T.H.; Verhagen, H.; Goldbohm, R.A.; van den Brant, P.A.; van Poppel, G. A review of mechanisms underlying anticarcinogenicity by Brassica vegetables. Chem. -Biol. Interact. 1997, 103, 79-129.

28. Pedroche, J.; Just, M.M.; Lqari, H.; Megias, C.; Giron-Calle, J.; Alaiz, M. Obtaining of Brassica carinata protein hydrolysates enriched in bioactive peptides using immobilized digestive proteases. Food Res. Int. 2007, 40, 931-938.

29. Cabello-Hurtado, F.; Gicquel, M.; Esnault, M.A. Evaluation of the antioxidant potential of cauliflower (Brassica oleracea) from a glucosinolate content perspective. Food Chem. 2012, 132, 1003-1009.

30. Romero-Jimenez, M.; Campos-Sanchez, J.; Analla, M.; Munoz-Serrano, A.; Alonso-Moraga, A. Genotoxicity and anti-genotoxicity of some traditional medicinal herbs. Mutat. Res. 2005, 585, 147-155.

31. Tasset-Cuevas, I.; Fernández-Bedmar, Z.; Lozano-Baena, M.D.; Campos-Sánchez, J.; de Haro-Bailón, A.; Muñoz-Serrano, A.; Alonso-Moraga, A. Protective effect of borage seed oil and gamma linolenic acid on DNA: In vivo and in vitro studies. PLoS ONE 2013, 8, e56986.

32. Lobo, V.; Patil, A.; Phatak, A.; Chandra, N. Free radicals, antioxidants and functional foods: Impact on human health. Pharmacogn. Rev. 2010, 4, 118-126.

33. Frei, H.; Würgler, F.E. Statistical methods to decide whether mutagenicity test data from Drosophila assays indicate a positive, negative, or inconclusive result. Mutat. Res. Environ. Mutagen. Relat. Subj. 1988, 203, 297-308.

34. Frei, H.; Würgler, F.E. Optimal experimental design and sample size for the statistical evaluation of data from somatic mutation and recombination tests (SMART) in Drosophila. Mutat. Res. Environ. Mutagen. Relat. Subj. 1995, 334, 247-258.

35. Baasanjav-Gerber, C.; Hollnagel, H.M.; Brauchmann, J.; Iori, R.; Glatt, H. Detection of genotoxicants in Brassicales using endogenous DNA as a surrogate target and adducts determined by 32P-postlabelling as an experimental end point. Mutagenesis 2011, 26, 407-413.

36. Hansen, M.; Møller, P.; Sørensen, H. Glucosinolates in broccoli stored under controlled atmosphere. J. Am. Soc. Hortic. Sci. 1995, 120, 1069-1074.

37. Heres-Pulido, M.E.; Duenas-Garcia, I.; Castaneda-Partida, L.; Santos-Cruz, L.F.; Vega-Contreras, V.; Rebollar-Vega, R.; Gomez-Luna, J.C.; Duran-Diaz, A. Genotoxicity studies of organically grown broccoli (Brassica oleracea var. italica) and its interactions with urethane, methyl methanesulfonate and 4-nitroquinoline-1-oxide genotoxicity in the wing spot test of Drosophila melanogaster. Food Chem. Toxicol. 2010, 48, 120-128. 
38. Musk, S.R.R.; Smith, T.K.; Johnson, I.T. On the cytotoxicity and genotoxicity of allyl and phenethyl isothiocyanates and their parent glucosinolates sinigrin and gluconasturtiin. Mutat. Res. Lett. 1995, $348,19-23$.

39. Gonçales, A.L.M.; Lemos, M.; Niero, R.; de Andrade, S.F.; Maistro, E.L. Evaluation of the genotoxic and antigenotoxic potential of Brassica oleracea L. var. acephala DC in different cells of mice. J. Ethnopharmacol. 2012, 143, 740-745.

40. Cartea, M.E.; Velasco, P.; Obregón, S.; Padilla, G.; de Haro, A. Seasonal variation in glucosinolate content in Brassica oleracea crops grown in northwestern Spain. Phytochemistry 2008, 69, 403-410.

41. Akao, Y.; Maruyama, H.; Matsumoto, K.; Ohguchi, K.; Nishizawa, K.; Sakamoto, T.; Araki, Y.; Mishima, S.; Nozawa, Y. Cell growth inhibitory effect of cinnamic acid derivatives from propolis on human tumor cell lines. Biol. Pharm. Bull. 2003, 26, 1057-1059.

42. Jakubikova, J.; Bao, Y.; Sedlak, J. Isothiocyanates induce cell cycle arrest, apoptosis and mitochondrial potential depolarization in HL-60 and multidrug-resistant cell lines. Anticancer Res. 2005, 25, 3375-3386.

43. Ludikhuyze, L.; Rodrigo, L.; Hendrickx, M. The activity of myrosinase from broccoli (Brassica oleracea L. var. italica): Influence of intrinsic and extrinsic factors. J. Food Prot. 2000, 63, 400-403.

44. Jie, M.; Cheung, W.M.; Yu, V,; Zhou, Y.; Tong, P.H.; Ho, J.W. Anti-proliferative activities of sinigrin on carcinogen-induced hepatotoxicity in rats. PLOS ONE 2014, 9, e110145.

45. Øverby, A.; Bævre, M.S.; Thangstad, O.P.; Bones, A.M. Disintegration of microtubules in Arabidopsis thaliana and bladder cancer cells by isothiocyanates. Front. Plant Sci. 2015, 6, doi:10.3389/fpls.2015.00006.

46. Tanaka, T.; Mori, Y.; Morishita, Y.; Hara, A.; Ohno, T.; Kojima, T.; Mori, H. Inhibitory effect of sinigrin and indole-3-carbinol on diethylnitrosamine-induced hepatocarcinogenesis in male ACI/N rats. Carcinogenesis 1990, 11, 1403-1406.

47. Smith, T.K.; Lund, E.K.; Parker, M.L.; Clarke, R.; Johnson, I.T. Allyl-isothiocyanate causes mitotic block, loss of cell adhesion and disrupted cytoskeletal structure in HT29 cells. Carcinogenesis 2004, $25,1409-1415$.

48. Hwang, E.S.; Lee, H.J. Allyl isothiocyanate and its $N$-acetylcysteine conjugate suppress metastasis via inhibition of invasion, migration, and matrix metalloproteinase-2/-9 activities in SK-Hep 1 human hepatoma cells. Exp. Biol. Med. (Maywood) 2006, 231, 421-430.

49. Lancashire, P.D.; Bleiholder, H.P.; van den Boom, T.; Langeluddecke, P.; Stauss, R.; Weber, E.; Witzenberger, A. A uniform decimal code for growth stages of crops and weeds. Ann. Appl. Biol. 1991, 119, 561-601.

50. Font, R.M.; del Río-Celestino, M.; Cartea, M.E.; de Haro, A. Quantification of aliphatic and índole glucosinolates in leaves of leaf rape (Brassica napus var. pabularia) by near infrared spectroscopy. Phytochemistry 2005, 66, 175-185.

51. Wathelet, J.P.; Wagstaffe, P.; Boenke, A. The Certification of the Total Glucosinolate and Sulphur Contents of Three Rapeseeds (Colza), CRMs 190, 366 and 367; European Commission: Brussels, Belgium, 1991.

52. Graf, U.; Würgler, F.E.; Katz, A.J.; Frei, H.; Juon, H.; Hall, C.B.; Kale, P.G. Somatic mutation and recombination test in Drosophila melanogaster. Environ. Mutagen. 1984, 6, 153-188. 
53. Rubin, G.M.; Yandell, M.D.; Wortman, J.R.; Gabor Miklos, G.L.; Nelson, C.R.; Harihanan, I.K.; Fortini, M.E.; Li, P.W.; Apweiler, R.; Fleischmann, W.; et al. Comparative genomics of the eukaryotes. Science 2000, 287, 2204-2215.

54. Graf, U.; Spano, M.A.; Rincon, J.G.; Abraham, S.K.; de Andrade, H.H. The wing somatic mutation and recombination test (SMART) in Drosophila melanogaster: An efficient tool for the detection of genotoxic activity of pure compounds or complex mixtures as well as for studies on antigenotoxicity. Afr. Newslett. Occup. Health Saf. 1996, 6, 9-13.

55. Lindsley, D.L.; Zimm, G.G. The Genome of Drosophila Melanogaster; Academic Press Inc.: San Diego, CA, USA, 1992.

56. Zhu, C.Y.; Loft, S. Effect of chemopreventive compounds from Brassica vegetables on NAD(P)H: Quinine reductase and induction of DNA strand breaks in murine hepa1c1c7 cells. Food Chem. Toxicol. 2003, 41, 455-462.

57. Abraham, S.K. Antigenotoxicity of coffee in the Drosophila assay for somatic mutation and recombination. Mutagenesis 1994, 9, 383-386.

Sample Availability: Samples of the plant material are available from the authors.

(C) 2015 by the authors; licensee MDPI, Basel, Switzerland. This article is an open access article distributed under the terms and conditions of the Creative Commons Attribution license (http://creativecommons.org/licenses/by/4.0/). 